\title{
ADMISSIONS TO BRITISH UNIVERSITIES
}

$\mathrm{T}$ HE second report of an ad hoc committee of the Committee of Vice-Chancellors and Principals of the Universities of the United Kingdom on Procedure for Admission of Students (pp. vi+3l. London : Association of Universities of the British Commonwealth, 1960. 2s.) deals first with the action taken by the universities on some procedural recommendations of an earlier report published in May 1958 by an ad hoc committee. Although the new system has been in operation for only one full year, it is already clear that a marked improvement has occurred. Indeed, 86 per cent of heads of schools answering the independent inquiry of the Joint Committee of the Four Secondary Associations about delays by universities were satisfied that there was no unreasonable delay, and 66 per cent were satisfied with the decisions themselves. Throughout the universities, all those concerned are showing the utmost willingness to co-operate in making the selection and admission of students as simple, fair and rapid a process as possible. As all those concerned, in universities and schools, become more accustomed to the new procedures, the improvement should continue, and to this end the Committee recommends that the normal date for the receipt of applications should continue to be January 31 of the year in which entry is desired (the preceding November 30 for medicine, etc.); constant care should be exercised to preserve standards of precision in letters making offers of places, and the great importance of making as many early decisions as possible is specially emphasized. The Committee also reviews some con- tinuing problems such as multiple interviews and clearing houses, and recommends that experiments should be tried, worked by volunteer professors in limited fields such as chemistry, physies. biology, medicine, dentistry, veterinary science. agriculture and law. Finally, it recommends that the admission of students generally be kept under review. The Committee of Vice-Chancellors and Principals has already invited this ad hoc committee to continue its consideration of future problems.

Figures for applications and admissions for 1959 show that applications to university institutions in England, Wales and Scotland were $117,300,7,600$ and 9,100 , respectively, and the corresponding admissions to first-degree courses were $14,960,1,650$ and 3,720 , respectively. As between the main categories, applications were distributed as follows : arts, 50,900 ; pre-science, 40,700 ; technology, 21,700; medicine, 13,100 ; dentistry, 4,500. The ratio of applications to the number of places available varies widely between individual universities; for example, from $6 \cdot 0$ to $11 \cdot 4$ in England, $3 \cdot 8$ to $6 \cdot 2$ in Wales, and 1.9 to 3.0 in Scotland, but no clear pattern, according to age or type of institution, emerged from more detailed examination of the figures.

Appended to the report is a brief guide for the sixth-former entitled "Getting into a University", containing the minimum information which any intending candidate needs before diseussing matters with those who will give him advice and before completing his application.

\section{INTERNATIONAL UNION FOR CONSERVATION OF NATURE AND NATURAL RESOURCES}

$\mathrm{R}$. LEVEQUE was appointed by Unesco to undertake a new mission to the Galapagos Islands. The purpose was to consolidate the basis for the establishment of a research laboratory, the primary objective of the Charles Darwin Foundation. He has now presented a report which contains a wealth of information about the destruction being wrought on the exceptional fauna of the archipelago*.

In his inventory of the present state of the animal populations, Levêque recalls that the sea-Iion has succeeded in holding its own in face of the depredations of fishermen, but the fur-bearing seal (Arctocephalus australis) is prey to exploitation which will soon lead to extinction if drastic measures are not taken. Biological study of the species must be a priority in the programme of research.

Concerning the bird populations, the maintenance of which is bound up with the survival of the shrub cover of the islands, Levêque is less pessimistic. The larger species call for attention : albatross, flightless cormorant, penguins and especially the flamingo, which is in keen demand for its feathers, and consequently vulnerable.

* Bulletin of the International Union for Consertation of Nature and Tatural Resources, 9, Nos. 1-2 (1960).
The author has nothing essential to add to the excellent material on reptiles previously compiled by Mr. Eibl-Eibesfeldt. Wild pig destroy the eggs of the sea iguana, but apart from this the latter species is practically without enemies; the land iguana is holding its own.

By far the most threatened species is the giant tortoise; the local position is desperate. The massacres continue, with the destruction of eggs by feral pigs, by trading shells, and extraction of oil. It appears necessary to destroy the foral pig if the tortoise is to be saved. Levêque calls for the establishment of a large park to be fenced off with barbed wire, and gives suggestion for its boundaries.

Crayfish are being captured on a reckless soale; a single boat recently brought in three tons of cray. fish tails in a few days; a thorough study of the biology of the species is required. Likewise, overfishing of the bacaleo will soon result in a serious depletion of this species.

The author lays strong emphasis on the disastrons consequences resulting from the introduction of exotic species to the Islands: dog, donkey, but especially pigs, "the worst enemy of the indigenous 